\title{
APPLICATION OF SIX SIGMA APPROACH FOR DELAY ANALYSIS IN CONSTRUCTION PROJECT
}

\author{
Arif Hussain', Ashish Kumar Paharia ${ }^{2}$ \\ ${ }^{1}$ PG scholar (Industrial Engg. \& Management) Takshshila Institute of Engineering \& Technology \\ Jabalpur (M.P.) \\ ${ }^{2}$ Assistant Professor, Takshshila Institute of Engineering \& Technology Jabalpur (M.P.)
}

\section{ABSTRACT}

Construction project organization combines the abilities and responsibilities of a traditional project management along with the skills and expertise of new construction approaches for the enhancement of the projects in construction industry. As because construction projects are always changing, the challenges faced in the course of executing construction projects that effects any project is Delays and disruptions. Delays as well as disruptions are sources of potential risks can be minimized only when their causes are identified. Construction delays can be considered as time lag in completion of activities from a fixed time as per contract and finally effects the factors such as social, financial, technical, economic, legal, construction, resource and commercial factors. The purpose of this research is to assess root causes and effects of delays in construction projects, and find the solution with a quality tool known as Six Sigma. Six Sigma's endeavor is to eliminate waste and inefficiency, in construction, production, manufacturing and services, thereby increasing customer satisfaction by delivering what the customer are most expecting. This study was carried out based on literature review and a questionnaire survey, in this study two sampling techniques were used to select respondents namely: purposive and random sampling. The questionnaire survey was distributed to the target respondent in different construction sites nearby Jabalpur Madhya Pradesh, and interviewed the personnel who are mainly associated with the constructional business. Findings reveals that the main causes of delays and disruptions are categories in to two factors as external and internal. External factors are those which can delay a project such as weather, governmental interference, labour strikes etc. And internal delays are those one which usually causes due to inadequate circumstances between owner, consultant, contractor, labours, and resources. This study leads to the main causes of internal delay are 1. Improper planning of contractor 2. Poor site management by contractor 3. Inadequate experience 4. Lack of resources and equipment availability 5. Untimed payment to the personnel 6. Material shortage 7. Inadequate drawings and blue prints of projects. 8 lack of proper communication between owner, consultant and contractor. Finally this study concludes construction projects at immense menace that have an effect on their performance and tried to solve those complicated situations with the quality tool called Six Sigma. It is therefore recommended that adequate construction timely issuing of information, budget, finalization of blue prints or design of project and proper project management skills should be the main focus of the parties in project execution process.

Key Words: Construction Projects, Delay, Six Sigma, DMAIC, DMADV

\section{INTRODUCTION}

The successful execution of constructional projects management combines the responsibilities of keeping them within estimated cost and prescribed schedule. Project management depends upon the methodology that requires skills and expertise of the construction industry and sound engineering judgement. Because construction projects are always new and changing, so it's hard to forecast the 
project with certainty of accomplishment. A successful construction project management desires a large vary of Endeavour, skills and talents to manage various personnel and projects. The ability of leading and controlling of constructional projects are essential therefore on be maintaining the principles of budgeting, finance, organization, scheduling, conflict, and legal problems through coordinating human and material [8].

\subsection{Defining Constructional Delays}

As the modern development grows up, it enhances the construction business growth. This also leads to the situation of challenges of completion of projects within due time and cost. One of the crucial problems in constructional project is delay for the completion of project. This problem of delay is quite common in construction projects, but is more palpable in the traditional type of contracts. Delays in project are dislike to owners, consultant or contractor, because it leads to calculated cost and time of the project goes in vain. However, many projects experiences extensive delays due to unstructured construction scheduling, quality control, contract management, procurement management and construction finance management and thereby damage the initial time and cost estimates of project. Delay in construction projects causes due to many reasons. Various factors responsible for delay in completion of constructional projects in due time and specified cost are categorised as 1 . Client driven delay 2. Contractor delay 3. External consultant delay 4. Political issues 5. External Conditions 6. Project condition etc. Delays in construction are always bringing significant losses on project cost, and hindrance to completion of a project.

\subsection{Types Of Construction Delays}

Constructional Projects are most probably alienated into many category of delay. Delay basically refers to the work which is happening after the time than planned, specified, and expected for the completion of project. Delays are mainly classified into four categories [8].

- Critical delay or Non-Critical delay

- Excusable delay or Non-Excusable delay

- Compensable delay or Non-Compensable delay

- Concurrent delay or Non-Concurrent delay

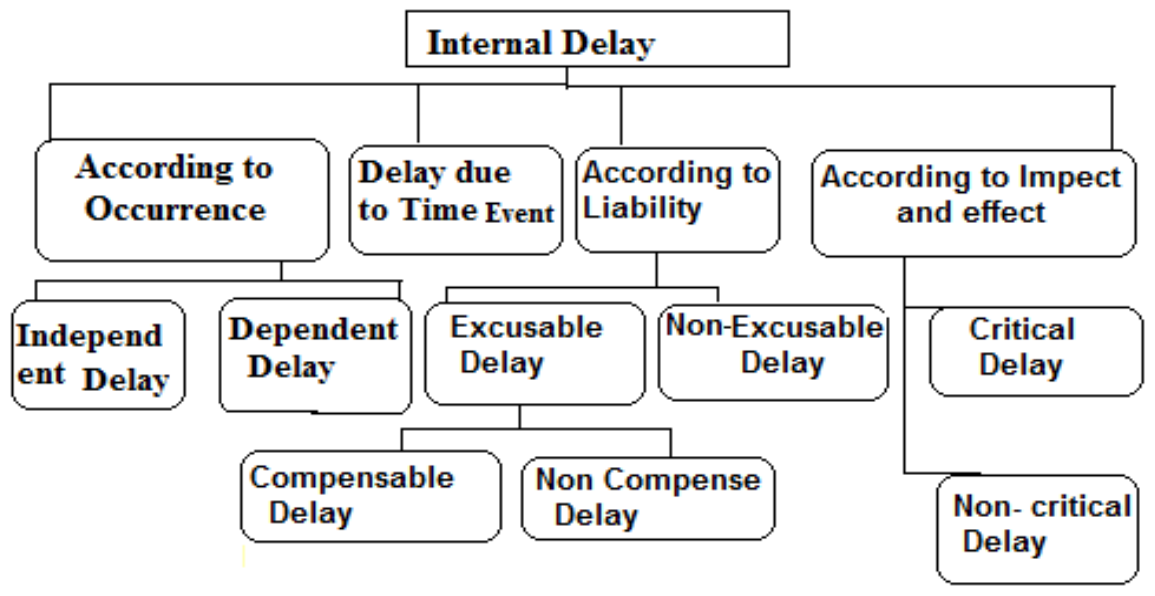

Figure: 1.2. Types of Internal Delays

\subsection{Introduction of Six Sigma}

Six sigma is recognized as a statistical category of quality tool that measures a process or solve problems in terms of defects for basic process improvements. Six sigma is adopted within the quality 
management to enhance the comparison and to construct a framework for process improvement of the performance of service organizations. This statistical quality tool mainly based on understanding the customer necessities, requirements and expectation, well-organized use of facts and statistics analysis, and integrated approach to improving, managing and establishing innovative business, service and manufacturing processes [11].

\subsection{Significance of Six Sigma}

Six sigma implies measures a process in terms of defects and maintenance of the desired quality inprocesses and end-products. Achieving six sigma levels means translates to about 2 Defects per Billion Opportunities (DPBO) if number of errors or defects is find out in billions, and or 3.4 Defects per Million Opportunities (DPMO) if the errors or defects are calculated in terms of millions. It has its base in the concept of probability and distribution in statistics that it strives upon the conclusion how to eliminate the errors and get as close to "zero defects" as possible and particularly $99.99966 \%$ or a failure rate of 3.4 parts per million of product articulated[15].

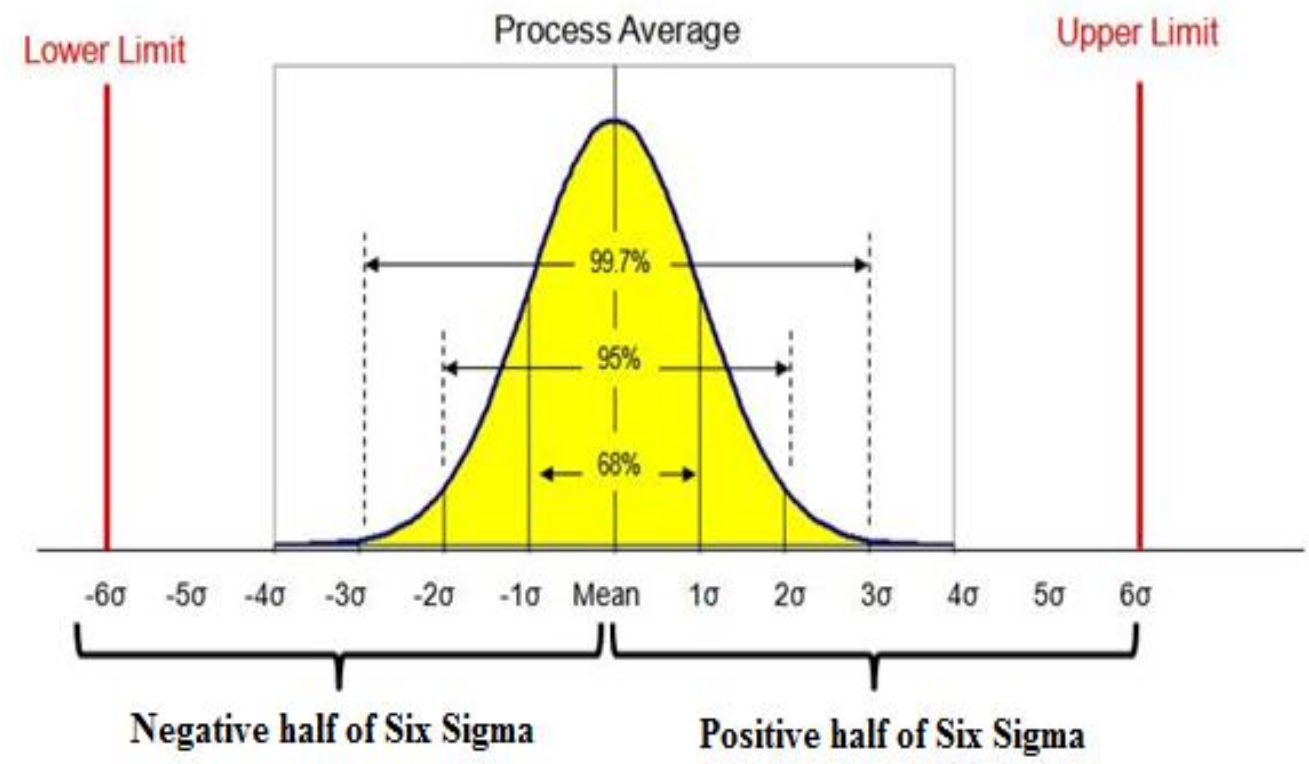

Figure: 2.1. Normal distribution curve of Six Sigma

The process of Six sigma is a highly restricted that helps to focus on developing and delivering close to-perfect products and services. These disciples is taken in to progression of defects Per Million Opportunities (DPMO) by applying the method called Define, Measure, Analyze, Improve and Control or in short DMAIC. In this method the whole procedure of the system is re-established and the function is compared up to the ways at different situation for the work in progress. For the DMAIC methodology, calculation of process is doing through finding the value of standard deviation and sigma value. The process of DMAIC is considered to be temporary values as the data simply contains common cause variations. The adequate process data can be determined by the factors which are most appropriate for process control. Now these days a new method is in the phase of developing stages, is called Design for Six Sigma or DFSS. The goal of DFSS is to build up a new process, product or service that is defect-free in the views of the customer. A number of consulting organizations have invented references for DFSS like IDOV (Identify, Design, Optimize and Validate) and DMADV (Design, Measure, Analyze, Design and Verify). These procedures are indented for the effective 
utilization of the recourses, management of the personnel along with the work process enhancement [2].

\section{LITERATURE REVIEW}

\section{Rohini, R., Mallikarjun, J.(2011)}

This study proposes the DMAIC Six Sigma approach of Define, Measure, Analyze, Improve/Implement and Control (DMAIC) to improve the process in the Operation Theatre of a corporate multi specialty hospital in Bangalore, India. The DMAIC approach showed a wider application and how the healthcare organization can achieve competitive advantages, efficient decision-making and problem-solving capabilities within a business context. The paper identifies each stage in detail, discusses the tools required and points out the limitations to the success of the improvement initiatives. The paper develops a Design DMAIC Model that can be used as a template for improving the Operation Theatre Process in hospitals. Six Sigma is complimentary to other initiatives such as ISO, JACHO,TQM, NABH etc. The study recommends many OT related solutions for framing policies, for consultants and for supportive staff, engineering and IT services.

\section{Saad Hegazy(2012)}

Choosing the delay analysis is an important part of the claims industry. Many techniques are used in the UAE, and with the involvement of many factors the chosen practice became more important to define the delays. Contractors pay a lot to the specialist to prove their right using delay analysis methodologies DAMs and they submit this as extension of time (delay claim), trying to maximize their benefits. Meanwhile the client is trying to use other DAMs to try to neglect certain facts which increase the dispute with the contractor. In this review we will discuss the delay claims in the construction industry in UAE and the approach for choosing delay analysis methodology.

\section{Ratnaningtyas, D. D., Surendro, K.(2013)}

Hospital provide a number of health services and proper health facilities for society, one of the healthcare is inpatient. Because of the daily high demand of inpatients healthcare in a day, some hospitals seems too overwhelmed to control the information flow. Mainly, hospital already used Hospital Information System (HIS) for helping managing information flow. But some of it does not really care about the quality of information. Information quality is a key element to determine the level of healthcare in hospital. By the improvement of information quality, the quality of healthcare would improve to support the patient's satisfaction. A method used for information quality improvement is Six Sigma. Six Sigma could be used for reducing information variance in healthcare, especially information that used in Hospital Information System.

\section{Tenera, A., Pinto L. C.(2014)}

The paper proposes a Lean Six Sigma (LSS) project management improvement model supported by the DMAIC cycle and integrating an enlarged and adapted set of statistical tools, given the nature of the project management main variables and the involved processes. The proposed model was tested in a Portuguese telecommunication company context which project management processes system are based on Project Management Institute (PMI) standards. The model allowed identifying company's main project management problems and associated causes and the selection of the causes to be first attended. The proposed model also permitted to systematically address the actions and solutions to be implemented in order to keep, in thelong run, the continuous improvement of the project management processes in the organization. 


\section{Vasilyeva-Lyulina, A., Onishi, M. \& Kobayashi, K. (2015)}

Delay is quite common in construction project. A variety of factors contribute to the delay of project completion in the complex interdependencies of a number of tasks. Hence determining the contractual responsibility of delay is the most likely source of dispute in construction projects. Methods used for forensic investigation of delay are called as 'delay analysis methods'. Although authoritative societies such as SCL (Society of Construction Law) and AACEI (Association for the Advancement of Cost Engineering International) have published guidance for implementing delay analysis methods, those are explained by a natural language, i.e. English, not by a formal language. On the other hand, process control of construction projects heavily relies on CPM programming based on the network modelling technique of which concept is described in a formal manner. The ambiguity of methods due to the lack of guidance on delay analysis methods described in a formal language may allow delay analysts to implement in different ways. Utilizing the mathematics as a formal language to explain delay analysis methods should contribute to reduce the degree of ambiguity of delay analysis methods and hence the possibility of dispute occurrence. This paper aims to formalizing delay analysis methods commonly applied in practice employing the mathematical language.

\section{METHODOLOGY}

This work includes Questionnaire Methodology for finding out the sources of delay and shorting the problem.

The Survey questionnaire is designed based to use Likert Scale on the aim of the study, to find out the result of the delays and causes of delays in construction projects on overall project. The Survey is framed in such a way that the personal prospects of different personnel involved in different projects is collected and analyzed. The questionnaire mainly consists of three sections as detailed below.

1. Background of Respondent - This is to collect the basic information about the respondent. (Experience, Designation, etc)

2. Delays Causes - This is used to collect the data on different causes of the delays happened in that distinct project.

3. Effects of Delays - Using these questions to evolve out the effects of the delays on the project are identified.

4.

In this work a Questionnaire of 20 questions has to be prepared from different traits and areas of process from construction system, for purpose of obtaining information regarding opinion of the Personnel. These questions were asked from various personnel in the field of different construction terrenes. Questionnaire were send and distributed up to 500 sheet out of those questionnaire received only $70 \%$ of the sheets back that is almost 350 sheets. Out of those questionnaire $5 \%$ sheets were of no use because of incomplete nature.

In this work, used 5 point scale, which are assigned to degree of satisfaction level of the respondent with regard to the requirement of the Construction project.

1

Very least

Important
2

Least Important
3

Important
4

Very Important
5

Most Important

(On Priority) 


\subsection{Delay Analysis Techniques}

3.3.1. Literature on this analysis technique based: The data analysis is determined to establish the relative importance of various factors that contribute to causes, effects, and minimization if construction delays (Divya.R , 2015).

Analysis of data consists of the following:

1) Calculating the Relative Importance Index (RII)

2) Ranking of factors in each category based on the Relative Importance Index (RII)

Where,

$$
R I I=\frac{\sum W}{A * N} * 100
$$

RII is the Relative Importance Index,

$\mathrm{W}=$ weighting given to each factor by the respondents (ranging from 1 to 5 ),

$\mathrm{A}=$ highest weight (i.e. 5),

$\mathrm{N}=$ total number of respondents.

Table 3.1: Table of questionnaire showing the probable causes for delay in construction projects and weight given by the respondents along with Relative importance.

\begin{tabular}{|c|c|c|c|c|c|c|c|}
\hline \multirow[t]{3}{*}{ S.No } & \multirow[t]{3}{*}{$\begin{array}{l}\text { Probable Causes for Delay in } \\
\text { Construction Projects }\end{array}$} & \multicolumn{5}{|c|}{$\begin{array}{l}\text { Weight out of } 354 \\
\text { Respondent }\end{array}$} & $\begin{array}{l}\text { RII (Relative } \\
\text { importance) }\end{array}$ \\
\hline & & \multicolumn{5}{|c|}{ Scale value $\min =1, \max =5$} & \multirow{2}{*}{$\begin{array}{l}R I I= \\
\frac{\sum W}{A * N} * 100\end{array}$} \\
\hline & & 1 & 2 & 3 & 4 & 5 & \\
\hline 1 & $\begin{array}{l}\text { Indicate the type of organization. Working } \\
\text { experience. }\end{array}$ & 196 & 91 & 42 & 25 & NA & 0.510204 \\
\hline 2 & $\begin{array}{l}\text { The confusing and ambiguous } \\
\text { requirements of Clients with Inadequate } \\
\text { definition of substantial completion would } \\
\text { cause impact in time delay and cost } \\
\text { overrun of the projects. }\end{array}$ & 46 & 102 & 126 & 54 & 26 & 0.793651 \\
\hline 3 & $\begin{array}{l}\text { The improper feasibility study providing } \\
\text { by the Client such as Original contract } \\
\text { duration is too short, would cause impact } \\
\text { on time and cost overrun of the project. }\end{array}$ & 8 & 135 & 101 & 84 & 26 & 0.740741 \\
\hline 4 & $\begin{array}{l}\text { Too many scope changes and constructive } \\
\text { changed orders by owner during } \\
\text { construction would cause impact on time } \\
\text { delay and cost overrun of the project. }\end{array}$ & 12 & 106 & 126 & 85 & 26 & 0.795893 \\
\hline 5 & $\begin{array}{l}\text { The Client's Improper Instruction process } \\
\text { i.e Poor communication and co-ordination } \\
\text { by owner and other parties would cause } \\
\text { impact on time delay and cost overrun of } \\
\text { the project. }\end{array}$ & 2 & 14 & 21 & 141 & 176 & 0.005682 \\
\hline
\end{tabular}




\begin{tabular}{|c|c|c|c|c|c|c|c|}
\hline 6 & $\begin{array}{l}\text { Delay in progress payment by owner } \\
\text { would cause impact on time delay and cost } \\
\text { overrun of the project }\end{array}$ & 0 & 2 & 8 & 112 & 232 & 0.431034 \\
\hline 7 & $\begin{array}{l}\text { Slow responses from the Client } \\
\text { organization or Slowness in decision } \\
\text { making process by owner would cause } \\
\text { impact on time delay and cost overrun of } \\
\text { the project. }\end{array}$ & 44 & 57 & 145 & 92 & 16 & 0.689655 \\
\hline 8 & $\begin{array}{l}\text { Delay in approving shop drawings and } \\
\text { sample materials in progress by owner } \\
\text { would cause impact on time delay and cost } \\
\text { overrun of the project. }\end{array}$ & 12 & 45 & 48 & 102 & 147 & 0.680272 \\
\hline 9 & $\begin{array}{l}\text { Conflicts between joint ownership of the } \\
\text { project would cause impact on time delay } \\
\text { and cost overrun of the project. }\end{array}$ & 0 & 00 & 00 & 00 & 00 & 0 \\
\hline 10 & $\begin{array}{l}\text { Unavailability of incentives for contractors } \\
\text { for finishing ahead of schedule project } \\
\text { would cause impact on time delay and cost } \\
\text { overrun of the project. }\end{array}$ & 2 & 5 & 12 & 90 & 245 & 0.408163 \\
\hline 11 & $\begin{array}{l}\text { Difficulties in financing project by } \\
\text { contractor have an impact on time/cost of } \\
\text { the project. }\end{array}$ & 10 & 20 & 33 & 75 & 216 & 0.465116 \\
\hline 12 & $\begin{array}{l}\text { Delay in possession of site i.e Poor site } \\
\text { management and supervision by contractor } \\
\text { would cause an impact of time/cost. }\end{array}$ & 5 & 75 & 80 & 72 & 122 & 0.819672 \\
\hline 13 & $\begin{array}{l}\text { Late in reviewing and approving design } \\
\text { documents by consultants would cause an } \\
\text { impact of time/cost }\end{array}$ & 17 & 32 & 45 & 105 & 155 & 0.645161 \\
\hline 14 & $\begin{array}{l}\text { Mistakes and discrepancies in design } \\
\text { documents would cause an impact of } \\
\text { time/cost. }\end{array}$ & 56 & 84 & 112 & 102 & 0 & 0.892857 \\
\hline 15 & $\begin{array}{l}\text { Insufficient data collection and survey } \\
\text { before design would cause an impact of } \\
\text { time/cost. }\end{array}$ & 2 & 1 & 8 & 112 & 231 & 0.4329 \\
\hline 16 & $\begin{array}{l}\text { Shortage of construction materials in } \\
\text { market would cause an impact of } \\
\text { time/cost. }\end{array}$ & 122 & 89 & 58 & 12 & 73 & 0.819672 \\
\hline 17 & $\begin{array}{l}\text { Delay in material delivery by vendors } \\
\text { would cause an impact of time/cost. }\end{array}$ & 2 & 19 & 24 & 102 & 199 & 0.491156 \\
\hline 18 & $\begin{array}{l}\text { Delay in procurement of materials would } \\
\text { cause an impact of time/cost. }\end{array}$ & 3 & 12 & 121 & 85 & 42 & 0.613998 \\
\hline
\end{tabular}




\begin{tabular}{|c|l|l|l|l|l|l|l|}
\hline \hline 19 & $\begin{array}{l}\text { Low constructability of design by the } \\
\text { designer, Low productivity and efficiency } \\
\text { of equipment would cause impact on time } \\
\text { delay and cost overrun of the project. }\end{array}$ & 12 & 40 & 45 & 250 & 0.4 \\
\hline 20 & $\begin{array}{l}\text { Inadequate staff experience, Lack of high } \\
\text { technology mechanical equipment, within } \\
\text { the Project Management Team would } \\
\text { cause impact on time delay and cost } \\
\text { overrun of the project. }\end{array}$ & 22 & 35 & 75 & 210 & 0.48 \\
\hline
\end{tabular}

In this research work the basic methodology applied of SIX SIGMA is DMAIC to improve existing Construction processes which consists of the following five steps:

- Define the actual process of construction through the Questionnaire and further process on the data.

- Measure key aspects of the current process through calculating Relative Importance Index.

- Analyze the data to verify cause-and-effect relationships in the present construction business. To determine this mean of the RII is calculated through the normal distribution mathematical calculation.

- Improve or optimize the construction process based upon data analysis using techniques of Six Sigma and applying at different sites to check upon the mathematical and actual calculations.

- Control is essential to utilize the required result and maintain the optimized system to make sure that any deviations from aim are corrected before they effect in defects.

In this research work of SIX SIGMA the Define term is expressed through the questionnaire and taking the actual condition of the system through the response of the respondents. Then measure part is calculated through the calculation of RII. Now for analyzing purpose the data is processed through calculating the mean by simply sum all the RII observations and divide by the total number of observations. The standard equation for computing the mean is as follows.

\section{Where}

$$
\times=\frac{\sum_{i=1}^{n} \mathrm{X}_{\mathrm{i}}}{n}
$$

$X=$ Mean of Relative Importance Index.

$X_{i}=$ Observation $i, i, \ldots \ldots ., n$.

$\mathrm{n}=$ Number of observations.

Required Calculations of mean are as:

$X=\frac{0.510+0.793+0.740+0.795+0.0056+0.431+0.689+0.680+0.00+0.408+0.465+0.819+0.645+0.892+0.432+0.819+0.491+0.614+0.4+0.48}{20}$

$$
X=\frac{11.11583}{20}
$$

$\mathrm{X}($ Mean of RII $)=0.555791$

The Range of SIX SIGMA and Standard deviation: Another measure of variation is the standard deviation of relative importance index. The equation for calculating the standard deviation is Range is the variation between the largest and smallest observations in a set of data. 
Standard deviation is the statistic that measures the quantity of data dispersion around the mean.

Where,

$$
\boldsymbol{\sigma}=\sqrt{\frac{\sum_{i=1}^{n}\left(\mathrm{X}_{\mathrm{i}}-\mathrm{X}\right)^{2}}{n-1}}
$$

$\begin{array}{lll}\sigma & = & \text { standard deviation of the above calculation } \\ \mathrm{X} & = & \text { Mean } \\ \mathrm{X}_{\mathrm{i}} & = & \text { Observation } \mathrm{i}, \mathrm{i}, \ldots \ldots ., \mathrm{n} . \\ \mathrm{n} & = & \text { Number of observations. }\end{array}$

In this research work standard deviation $\sigma$ is calculated as:

$$
\sigma=\sqrt{\frac{\left(\mathrm{X}_{\mathrm{i} 1}-\mathrm{X}\right)^{2}+\left(\mathrm{X}_{\mathrm{i} 2}-\mathrm{X}\right)^{2}+\ldots \ldots \ldots \ldots}{\mathrm{n}-1}}
$$

$$
\begin{array}{ll}
\sigma & V_{\left[(0.045)^{2}+(0.185)^{2}+(0.240)^{2}+(0.550)^{2}+(0.124)^{2}+(0.134)^{2}+(0.125)^{2}+(0.147)^{2}+\right.} \\
\left.(0.090)^{2}+(0.1)^{2}+(0.264)^{2}+(0.090)^{2}+(0.337)^{2}+(0.123)^{2}+(0.264)^{2}+(0.064)^{2}+(0.058)^{2}+(0.156)^{2}+(0.076)^{2}\right] /(
\end{array}
$$

20-1)

$\sigma=\sqrt{(0.846 / 19)}$

Standard deviation $(\sigma)=\bigvee_{0} .044526=0.2110$

Six Sigma Curve: On the basis of above data progression following standard deviation curve is generated.

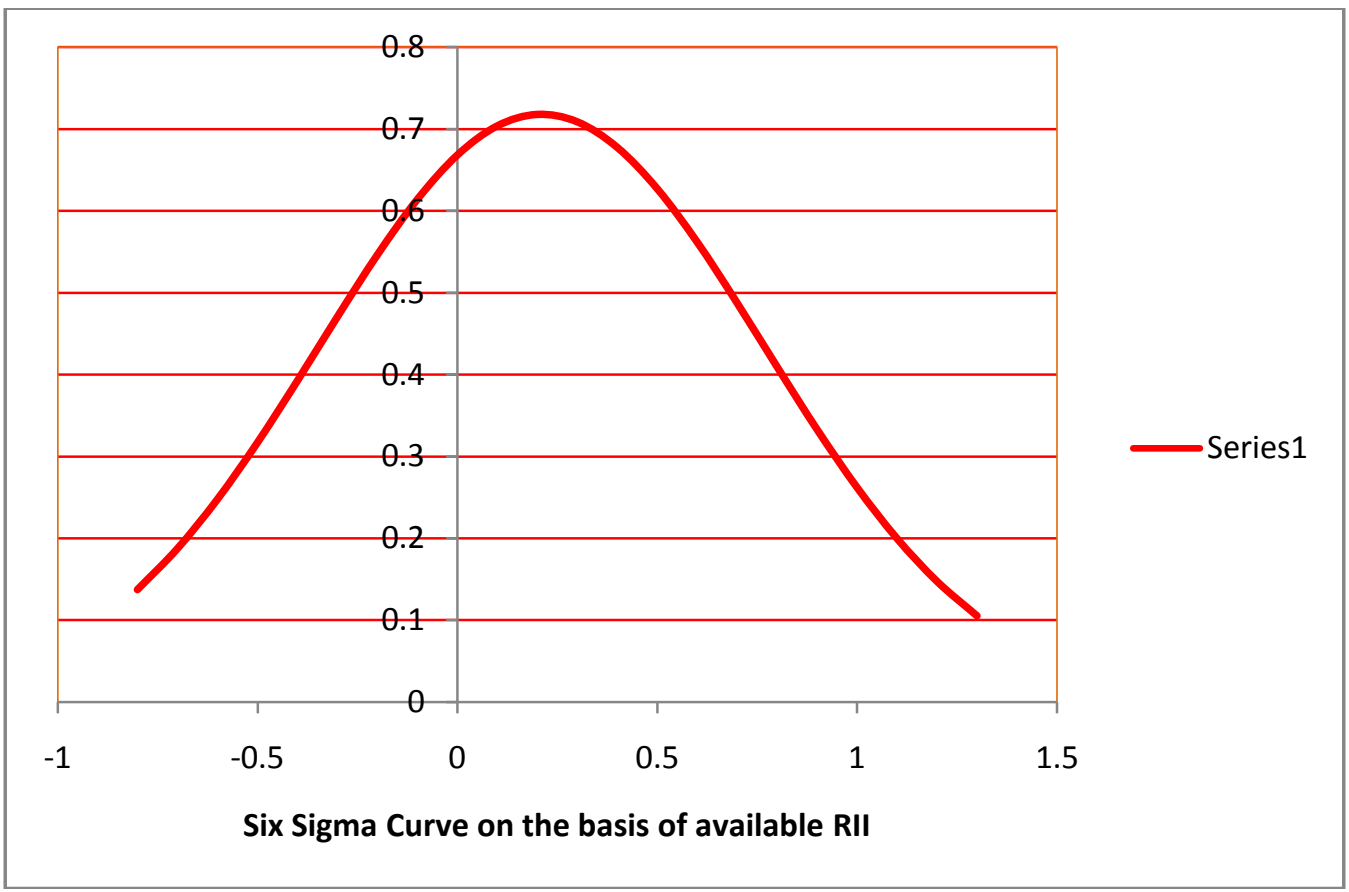

Figure 6.2: Six Sig Curve at mean of 0.555791 and standard deviation of 0.2110

On the basis of RII calculation, it is found that the factors given by the respondent in the questionnaire in terms of value more than 3 points must need the urgent requirement to be concerned upon. And following actions should be taken care of for some Critical X to improve the productivity of Six Sigma calculation. 


\section{(All actions for critical X factor are shown here):}

X1: Improve Supervision / Leadership of contractor and sub-contractors

- Deploy experienced project manager;

- Employ supervisor whose design is taken into broad-spectrum of construction projects

- foreman, who have the required experienced in the field of project.

- Hire Project Quality Engineer who estimate the entire construction projects with is course due time.

X2: Optimize process flow by increasing Resource Utilization in the construction projects according to site situations.

- Contribute Gantry Cranes for project production area for proper enhancing of resources.

- Add concrete bucket to allow simultaneous work on multiple tables for proper meson work.

- Start use of Ready-mix Trucks for maximum processes enhancement in grey concrete delivery.

- Add different shift work to recover schedule and utilize the men power in effective ways.

X3: Eliminate Waste through improved Inventory Management and control

- Reconfigure raw yard and stockyard for better access and control

- Reduce Inventory Level to as maximum as possible and within the mobile approach.

- Apply proper information to the employees such as Visual Controls to display product status and other codes for proper work features (red-curing day 1, yellow curing day 2, green ready for blasting).

- Status inventory and develop Inventory Logs records to track storage and deliveries in the project sites.

X4: Apply document Standard Work \& Improve Logistics in the project management.

- Prepare a record list of standard activities with clear specific roles, responsibilities and accountabilities Implementing Lean Six Sigma in Concrete application of Production Planning and Control.

- Measure cycle times of the process and reduce lead time by eliminating waste.

For further Improvement in the project the decisive factor had been done through the sigma control charts. In this the function of sigma is calculated through the Upper sigma limit (USL) through the value of mean by adding three times of standard deviation and Lower sigma limit (LSL) through the value by subtracting three time the value of standard deviation and on the basis of this the Sigma control graph is produced

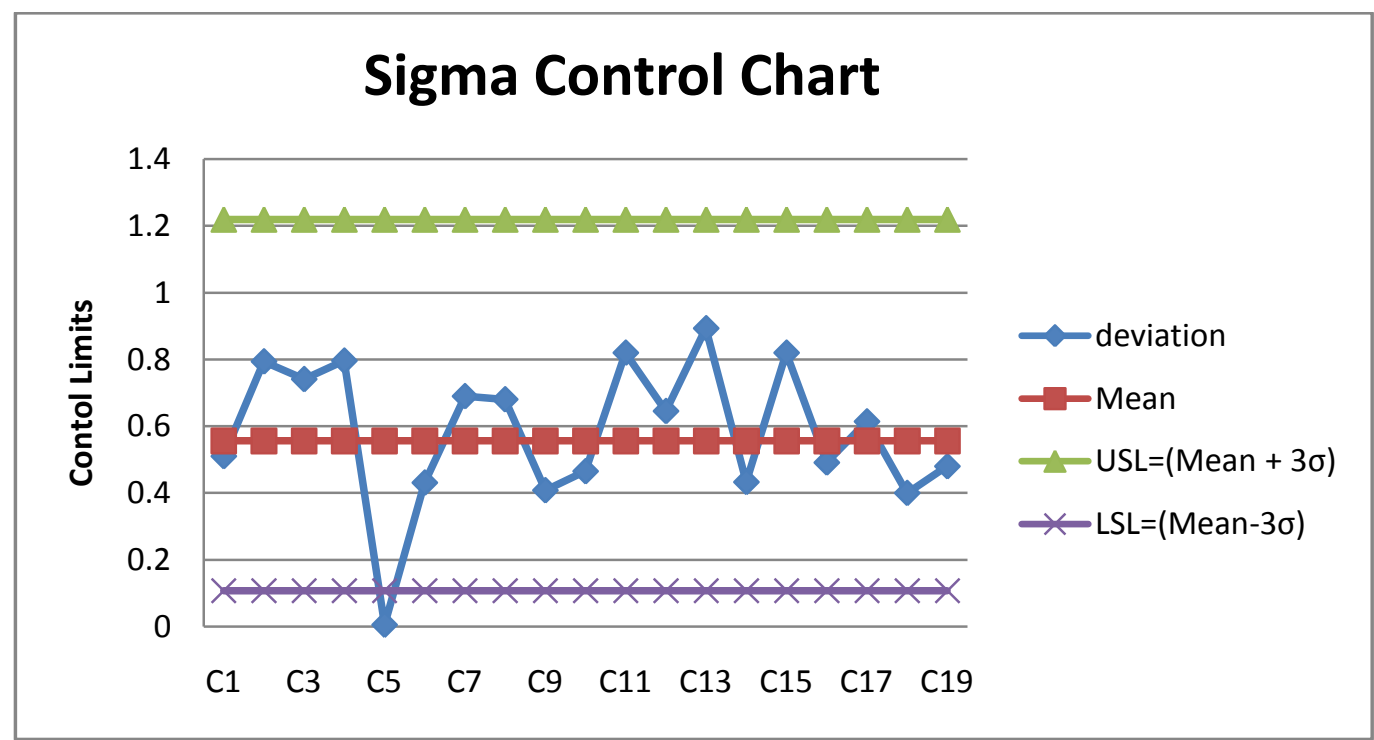

Further in result and discussion the interpreted results upon each individual aspects of respondent is checked upon and tried to cover it with proper sigma function. 


\section{RESULTS AND OUTCOME}

The Data Analysis and Interpretation is a process of inspecting, cleaning, transforming, and modeling data Specialization with the aim of discovering essential information, suggesting conclusions, and supporting decision-making by applying scientific tools. The process of evaluating data using analytical and logical reasoning has apply to examine each component of the data provided. This form of analysis is just including data management and visualization, in one of the many steps that must be completed the data analysis to address an important issue, in concerned areas of experiment, and reports the findings in a professional-quality report when conducting and concluding a research experiment. Research accomplishment and finalization is supposed to be when the Data from various sources is reviewed, gathered, and then analyzed to form some sort of conclusion or finding. There are a mixture of specific data analysis method, some of which include data mining, text analytics, business intelligence, and data visualizations. This work also concluded the specific results of the research interpretation, which is as follows.

Q1. Since how many years you are working in the company?
a.) Less than 5 yrs,
b.) $5-10 \mathrm{yrs}$,
c.) $10-15 \mathrm{yrs}$,
d.) more than 15 yrs

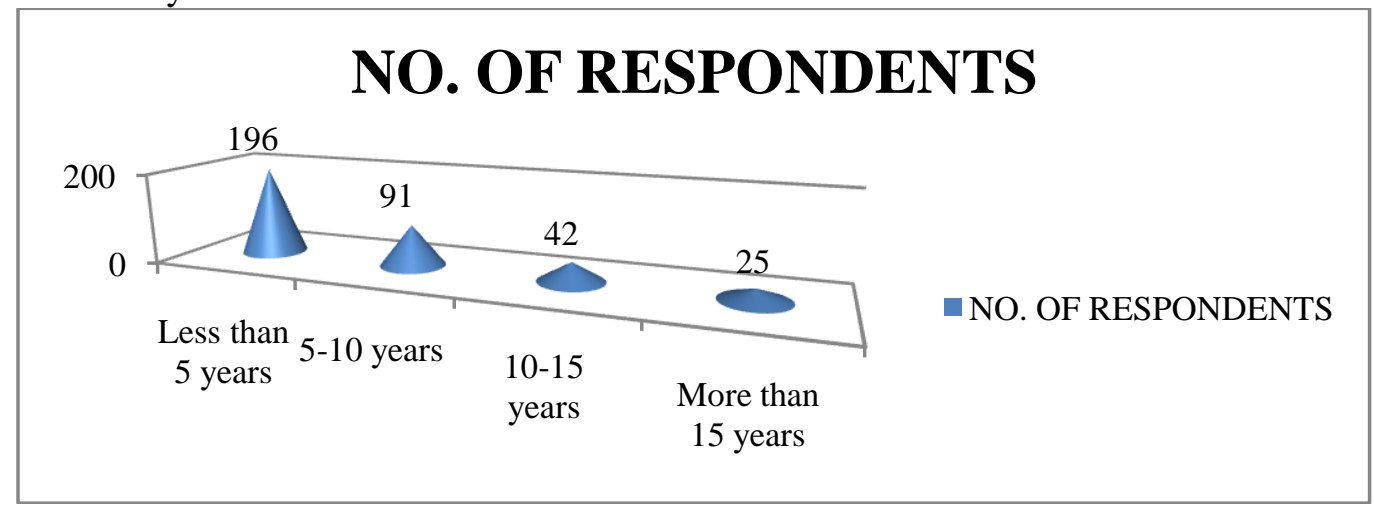

Figure 4.1: Figure showing working experience of the personnel.

Q2. The confusing and ambiguous requirements of Clients with Inadequate definition of substantial completion would cause impact in time delay and cost overrun of the projects.

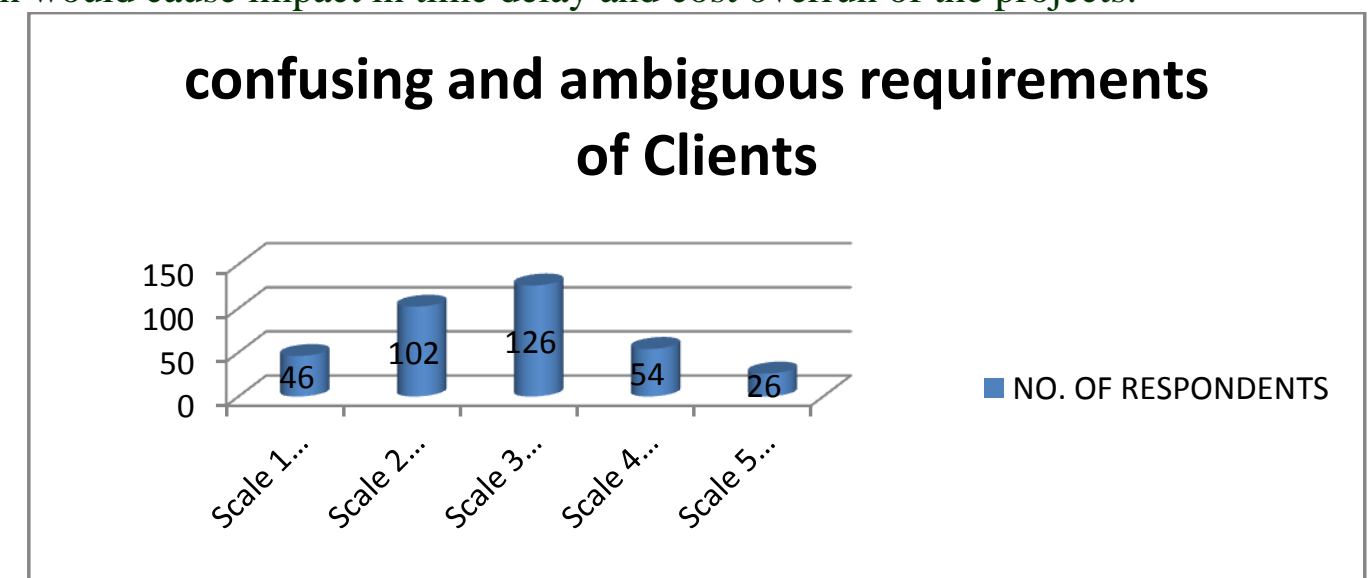

Figure 4.2: Figure showing the response of personnel on ambiguous requirements of clients. 
Interpretation: This graph represents about, happening of ambiguous requirement is moderate within the construction system.

Six Sigma Contraptions: According to six sigma description of DMAIC (Define, Measure, Analyze, Improve and Control) method Prioritize Activities is the best solution for this discrepancy. This is achieved by producing first the blueprint vision of the function which in the control fashion.

Q3. The improper feasibility study providing by the Client such as Original contract duration is too short, would cause impact on time and cost overrun of the project.
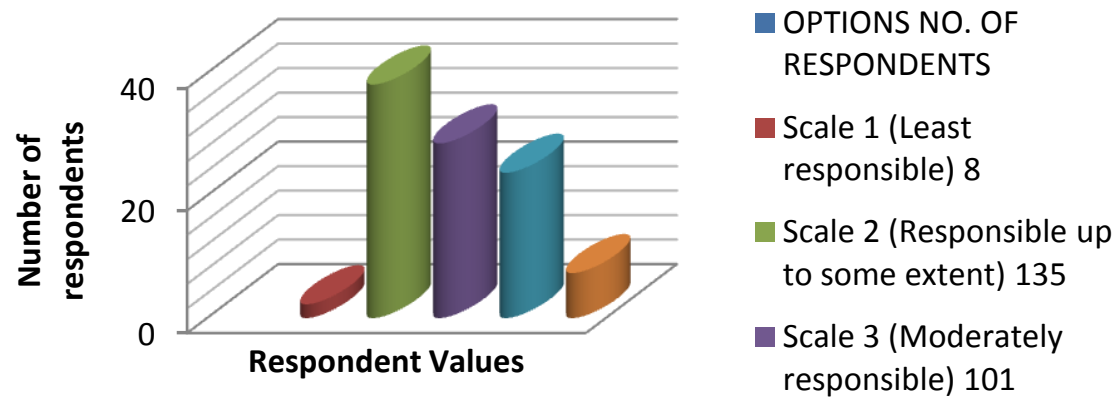

Interpretation: In this questionnaire the personnel responses about the improper feasibility study providing by the Client such as Original contract duration is too short, would cause impact on time and cost overrun of the project. This figure is showing the percentage of the personnel out of 354 responses.

Six Sigma Contraptions: Six sigma interpretations about this subject are to take the Right Measurements of the function of which is required to be accomplished. The graph is showing the function of six sigma application about the measurement of work.

Q4: Too many scope changes and constructive changed orders by owner during construction would cause impact on time delay and cost overrun of the project.

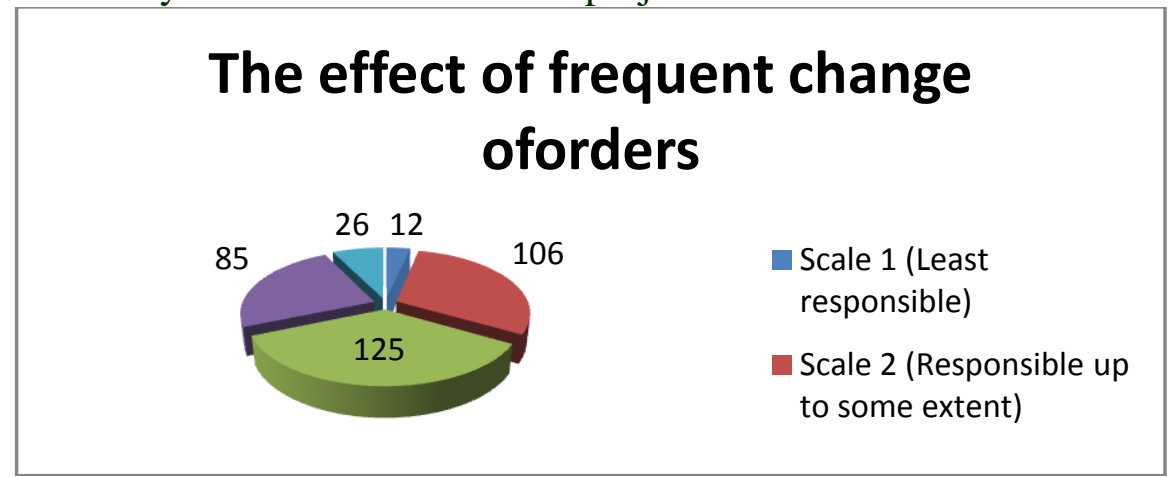

Figure 4.4: Figure showing the responses on effect of changing the prerequisite of construction orders.

Interpretation: This graph interprets about the frequent change of orders in construction system leads to the confusion and would cause impact on time delay and cost overrun of the project.

Six Sigma Contraptions: In this function Six Sigma Establishes Ownership and instruct the proper method for the system to propagate in the right direction and improvement activity, for the project goals, and personnel requirements. 
Q5. The Client's Improper Instruction process i.e Poor communication and co-ordination by owner and other parties would cause impact on time delay and cost overrun of the project.

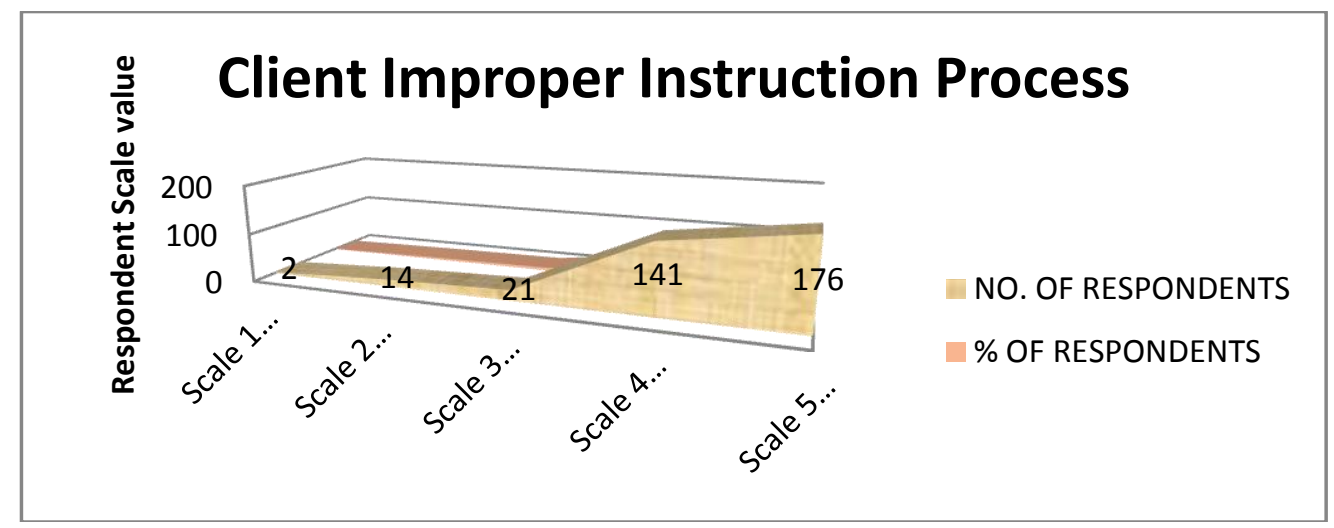

Figure 4.5: Figure showing the responses on Improper Instruction by the owner and their influence.

Interpretation: In this questionnaire the respondents shows their views on the Improper Instruction of details and function of conditions and requirements.

Six Sigma Contraptions: As Six Sigma is a data-driven quality approach used to improve processes. In this function the six sigma approach is utilized by Govern the Program of proper Data analysis before preceding the work. This function is known as Governance, in terms of DMAIC of Six Sigma.

Q6. Delay in progress payment by owner would cause impact on time delay and cost overrun of the project.

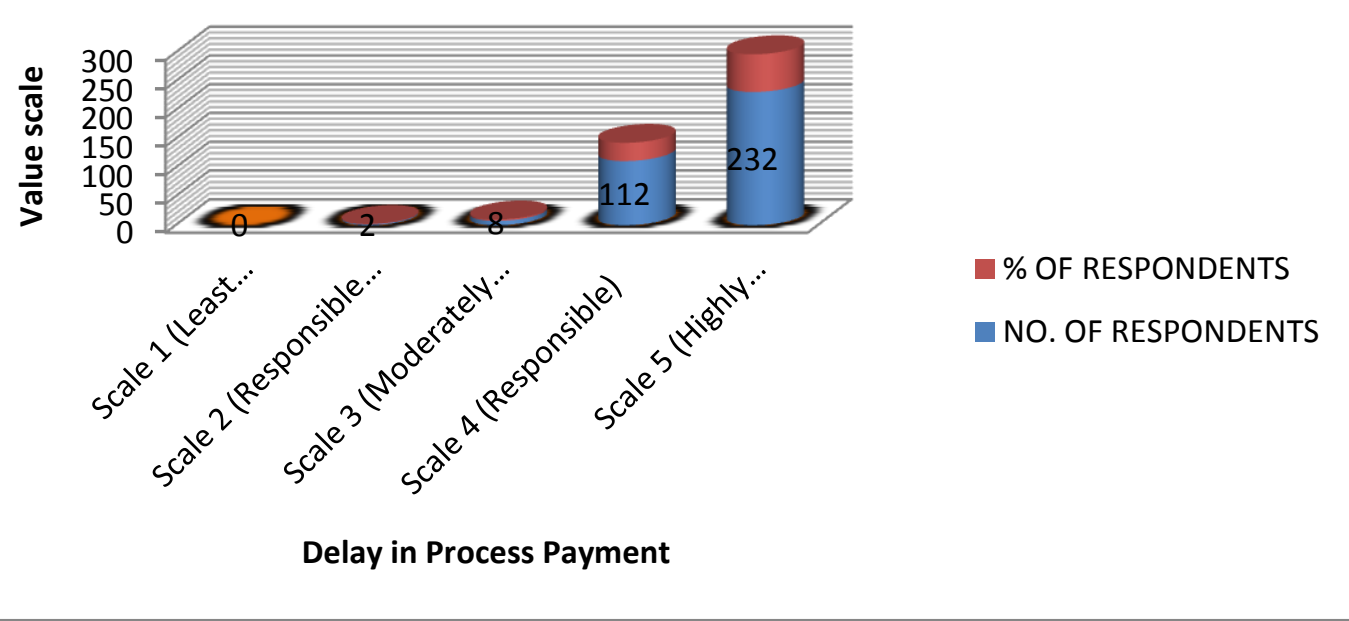

Figure 4.6: Figure showing the response value on delay in progress payment by owner and its effect.

Interpretation: Figure showing the respondent value on the work payment and its effect on the performance of labour or personnel.

Six Sigma Contraptions: In this function Key word for Six Sigma consideration is to Evaluate the cost and Execute the system in such a manner that the release of job payment on time so that no work is hindered. 
Q7. Slow responses from the Client organization or Slowness in decision making process by owner would cause impact on time delay and cost overrun of the project.

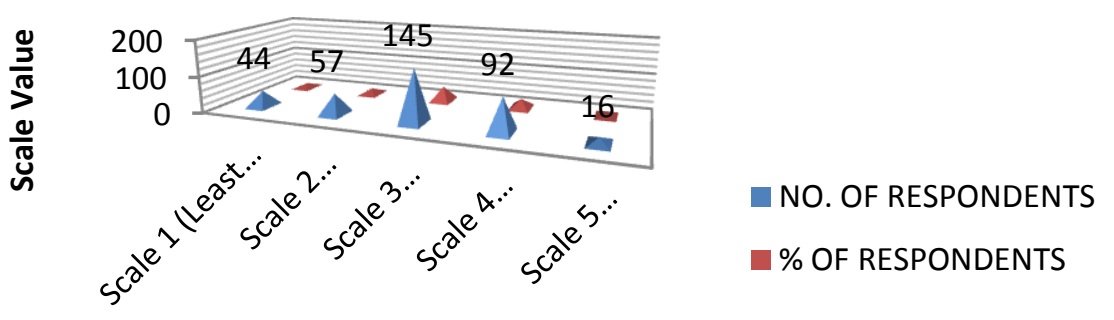

Slowness in Design making

Figure 4.7: Figure showing the response on slow responses from client in decision making process by owner.

Interpretation: The above table and graph showing the Slowness in decision making process by owner would cause impact on time delay and cost overrun of the project.

Six Sigma Contraptions: In six sigma consideration this function is short out through the Use Analytic Hierarchy Process (AHP) for Project Selection. The analytic hierarchy process creates a prearranged baseline for continuously improving decision making processes and progresses of work which results in higher levels of efficiency and effectiveness. Decision making is one of the main function in any kind of job or business and it should be relevant on time for this it is essential the owner have clear and sound vision and attain the decision making on perfect timing.

Q8. Delay in approving shop drawings and sample materials in progress by owner would cause impact on time delay and cost overrun of the project.

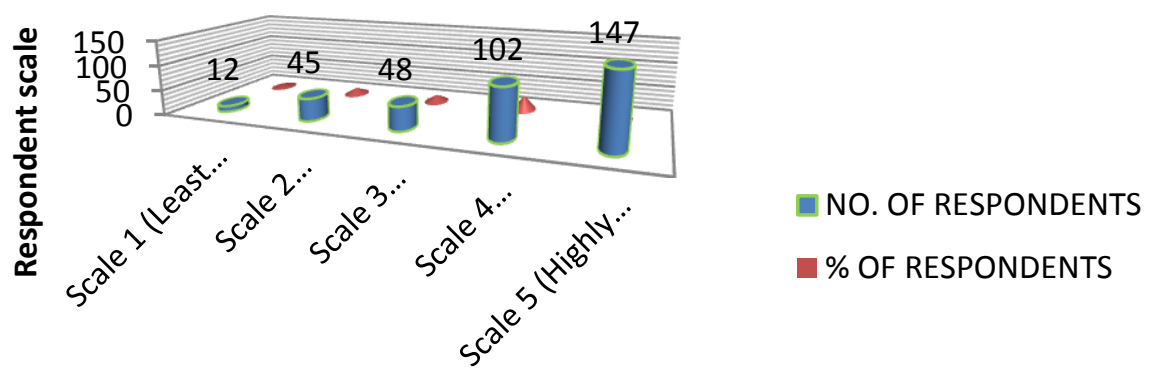

Delay due to approving shop drawings

Figure 4.8: Figure showing response on delay in approving shop drawings and sample materials and its effect.

Interpretation: The above table and graph showing the Delay in approving shop drawings and sample materials in progress by owner would cause impact on time delay and cost overrun of the project. 
Six Sigma Contraptions: In Six Sigma these situations are handled through deployment management, in which the assistance have to meet and manage such cynics, and the only means to oppose this pushback is to have a common vision across the organization.

Q10. Unavailability of incentives for contractors for finishing ahead of schedule project would cause impact on time delay and cost overrun of the project.

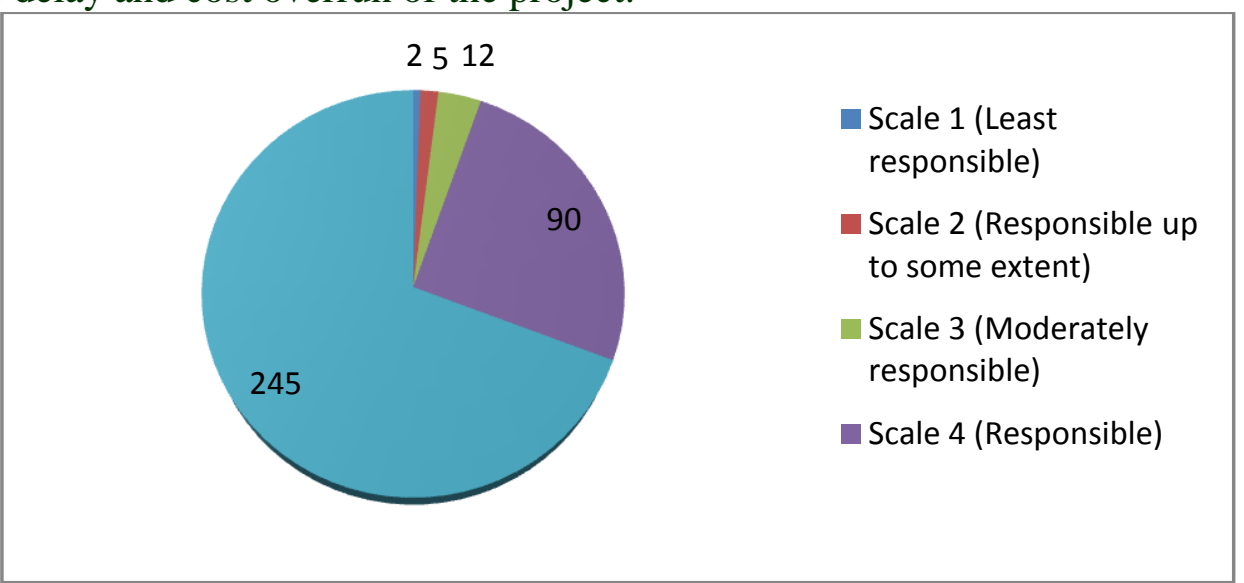

Figure 4.10: Figure showing the response on unavailability of incentives for contractors for finishing ahead of schedule project.

Interpretation: Above graph and figure showing the response of respondent on topic Unavailability of incentives for contractors for finishing ahead of schedule project would cause impact on time delay and cost overrun of the project.

Six Sigma Contraptions: Out of eight steps of performance in Six Sigma as 1) Burning platform and Shared vision 2) Maintain resources 3) Teach the essential requirement of function 4) Prioritize the function 5) Ownership and empowerment 6) Measurement 7) Governance and review 8) Recognition. In this situation the second step is prioritize for the sustaining the performance on sound manner.

Q11. Difficulties in financing project by contractor have an impact on time/cost of the project.

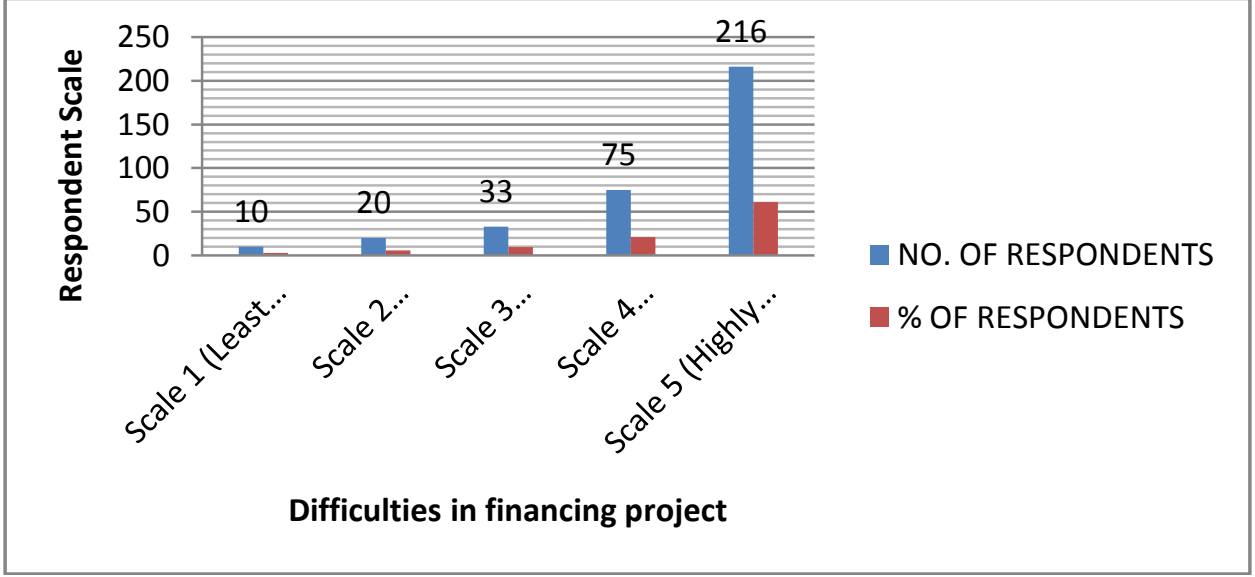

Figure 4.11: Figure showing response on difficulties in financing project by contractor and its effect. 
Interpretation: Above graph and figure showing response of respondent on the situation of difficulties in financing project by contractor have an impact on time/cost of the project.

Six Sigma Contraptions: In this situation the application of Six Sigma is proceed through the resource outlook and prioritize the insurance of necessary resources which is quite available and on the basis of which the function continuous.

Q12. Delay in possession of site i.e Poor site management and supervision by contractor would cause an impact of time/cost.

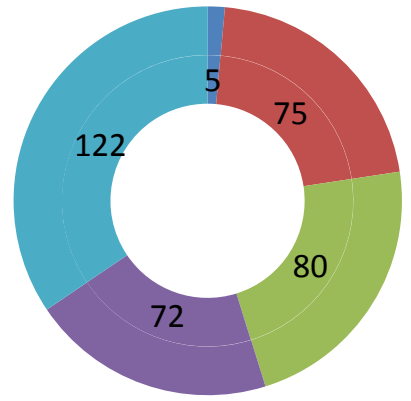

- Scale 1 (Least responsible)

- Scale 2 (Responsible up to some extent)

- Scale 3 (Moderately responsible)

- Scale 4 (Responsible)

Figure 4.12: Figure showing the response on delay in possession of site (poor site management) and effect.

Interpretation: Above table and graph showing the response of respondent on Delay in possession of site i.e Poor site management and supervision by contractor would cause an impact of time/cost.

Six Sigma Contraptions: Six sigma principles use numeric and statistical methods to reduce the delay and defects in output. The essential function of Six Sigma is implemented through the prioritization of project, training, team, plan, execute and evaluate the function to provide an effective way of development in construction.

Q13. Late in reviewing and approving design documents by consultants would cause an impact of time/cost.

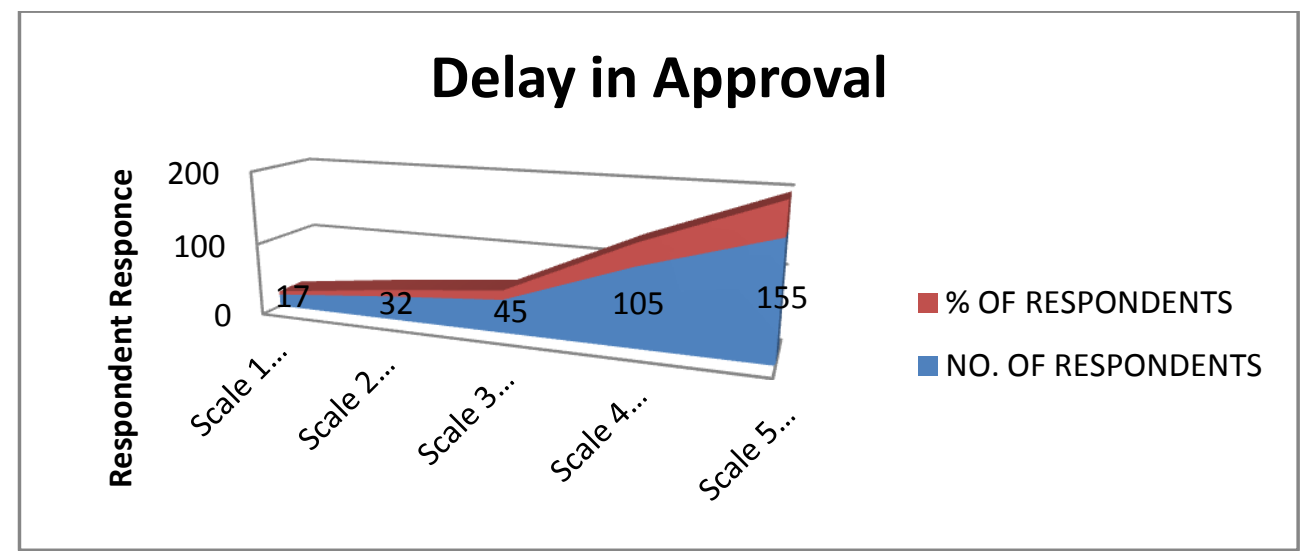

Figure 4.13: Figure showing the response of late in reviewing and approving design documents by consultant and it effect on construction projects. 
Interpretation: Above table and graph is showing the respondent response on late in reviewing and approving design documents by consultants would cause an impact of time/cost.

Six Sigma Contraptions: In this function, Six Sigma approach is made in the following steps as first step is executive training, second step Data measurement, next to it is Data Analysis, later the assessment of Quality Improvement under changed conditions and last is constant monitoring and control. When these steps is taken into consideration then the available function of construction system get systematize.

Q14. Mistakes and discrepancies in design documents would cause an impact of time/cost.

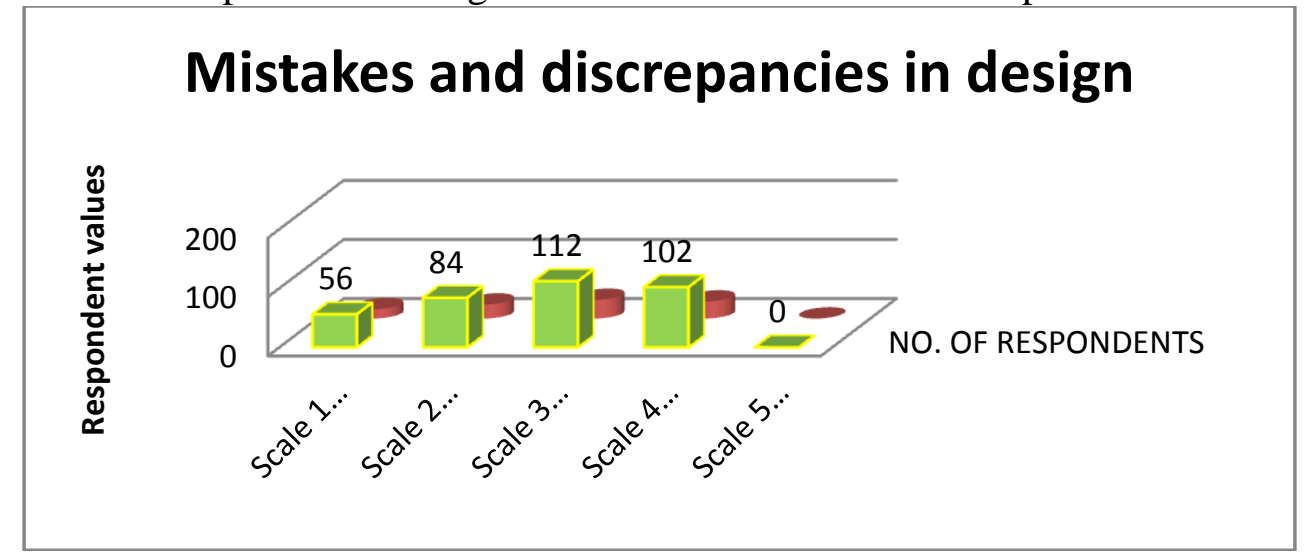

Figure 4.14: Figure showing the response on mistakes and discrepancies in design documents and their effects.

Interpretation: Above table and graph showing the respondent response on Mistakes and discrepancies in design documents would cause an impact of time/cost.

Six Sigma Contraptions: For minimizing the discrepancies in design and documents six sigma implementation can be done by following the steps as given 1) Establishing Management function 2) Proper information gathering 3) Proper training 4) Developing monitoring systems 5) Execution of projects.

Q15. Insufficient data collection and survey before design would cause an impact of time/cost.

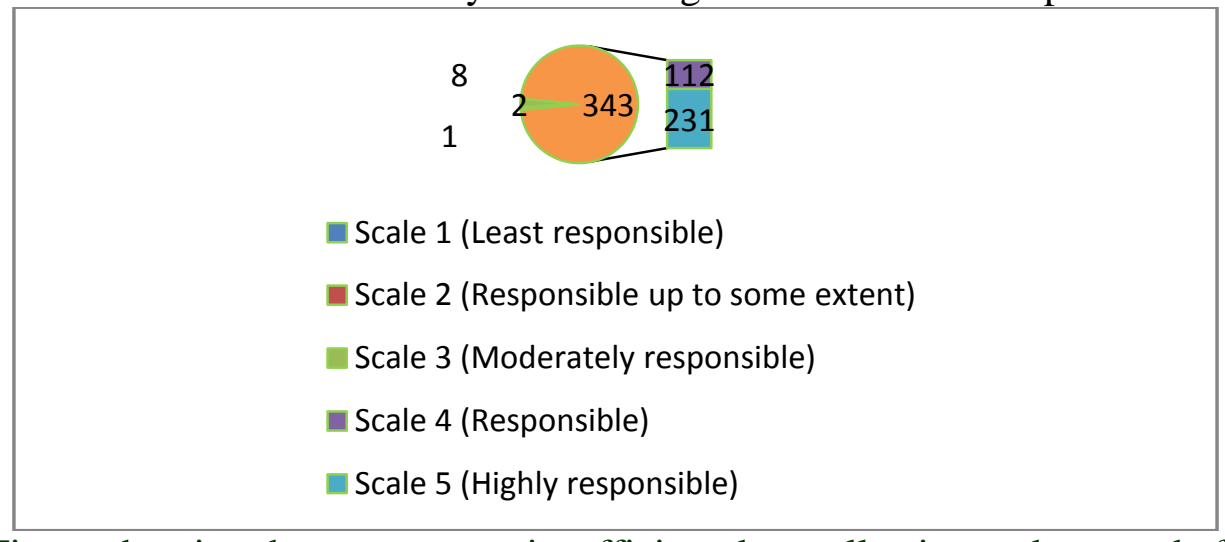

Figure 4.15: Figure showing the response on insufficient data collection and survey before design and its effect. 
Interpretation: Above table and graph showing the respondent response on insufficient data collection and survey before design would cause an impact of time/cost.

Six Sigma Contraptions: For maintaining the proper function of the projects the Six Sigma set down the following steps to follow for this function as given 1. Describe vision and mission 2. Describe value chains for the function of projects 3 . Analyze recourses 4 . Establish smart and ensured level metric goals 5. Indentify high potential areas for improvement.

Q16. Shortage of construction materials in market would cause an impact of time/cost.

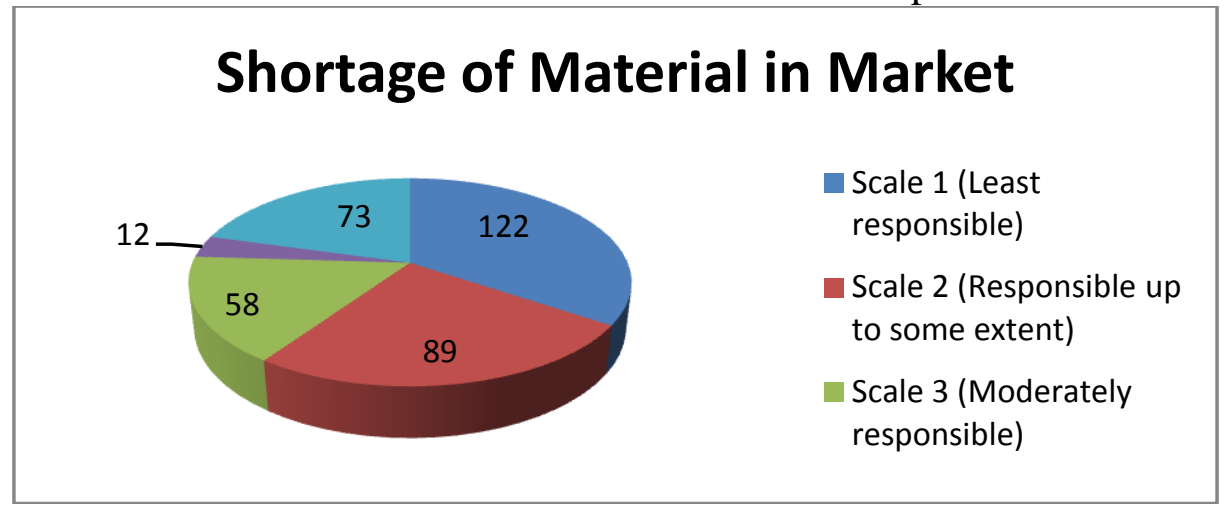

Figure 4.16: Figure showing the response on shortage of construction materials in market and its effect.

Interpretation: Above table and graph showing the respondent response on Shortage of construction materials in market would cause an impact of time/cost.

Six Sigma Contraptions: For this purpose the Six Sigma step towards implementing the accurate resource is the evaluation process, which should be executed thoroughly in order to assess the possible outcome of six sigma in that particular project.

Q17. Delay in material delivery by vendors would cause an impact of time/cost.

\section{Delay in material delivery by vendors}

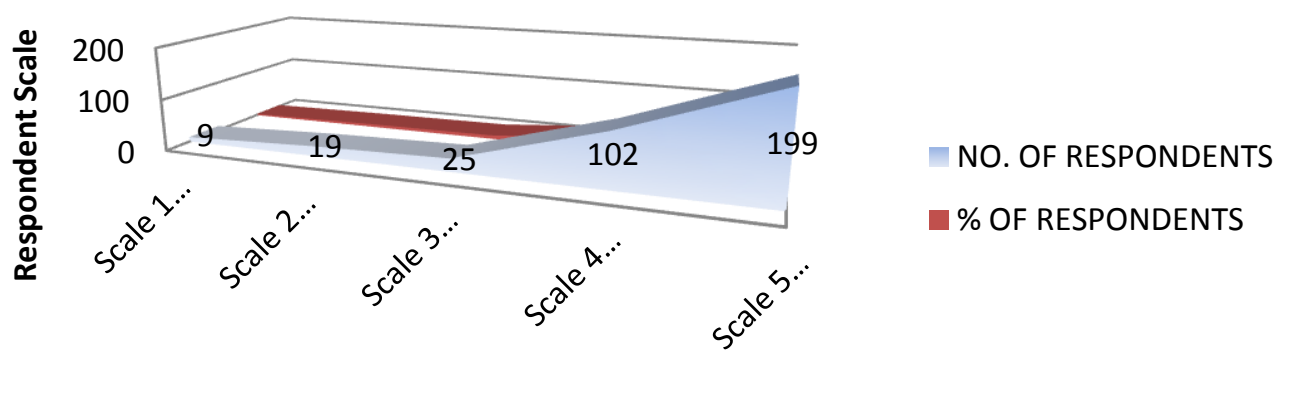

Figure 4.17: Figure showing the response on delay in material delivery by vendors and its effect in construction

Interpretation: Above table and graph showing the respondent response on Delay in material delivery by vendors would cause an impact of time/cost. 
Six Sigma Contraptions: For the best performance in this function the following Six Sigma steps should be following 1. Discovering the scopes of the projects 2. Decision making on each aspect of projects 3. Organise the Targets of project 4. Initializing the process of project

Q18. Delay in procurement of materials would cause an impact of time/cost.

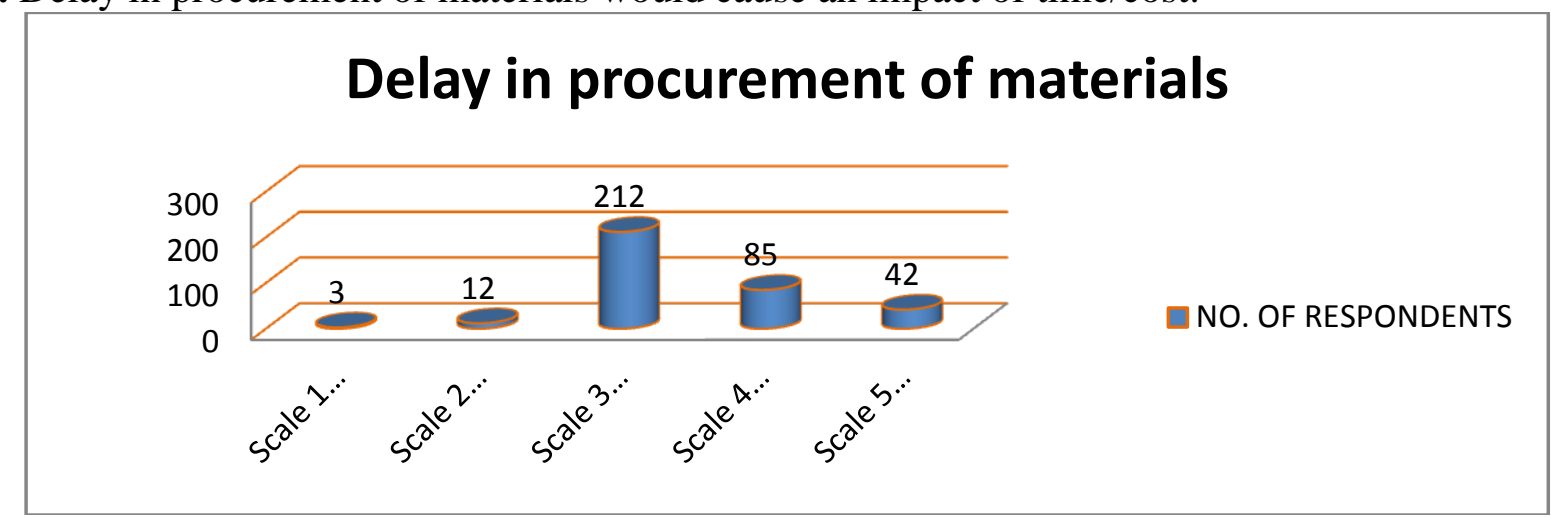

Figure 4.18: Figure showing the response on delay in procurement of materials and its effect on construction projects.

Interpretation: Above table and graph showing the respondent response on Delay in procurement of materials would cause an impact of time/cost.

Six Sigma Contraptions: A Six Sigma initiative occurs for this function in the following steps 1. Initialize Six Sigma by establishing goals and installing the proper infrastructure. 2. Deploy the initiative by assigning, proper training, and equipping the staff. 3. Implement projects and improve performance of projects by yielding financial results. 4. Development of the initiative to include additional organizational units. 5. Final function is to sustain the initiative through realignment, retraining, and evolution.

Q19. Low constructability of design by the designer, Low productivity and efficiency of equipment would cause impact.

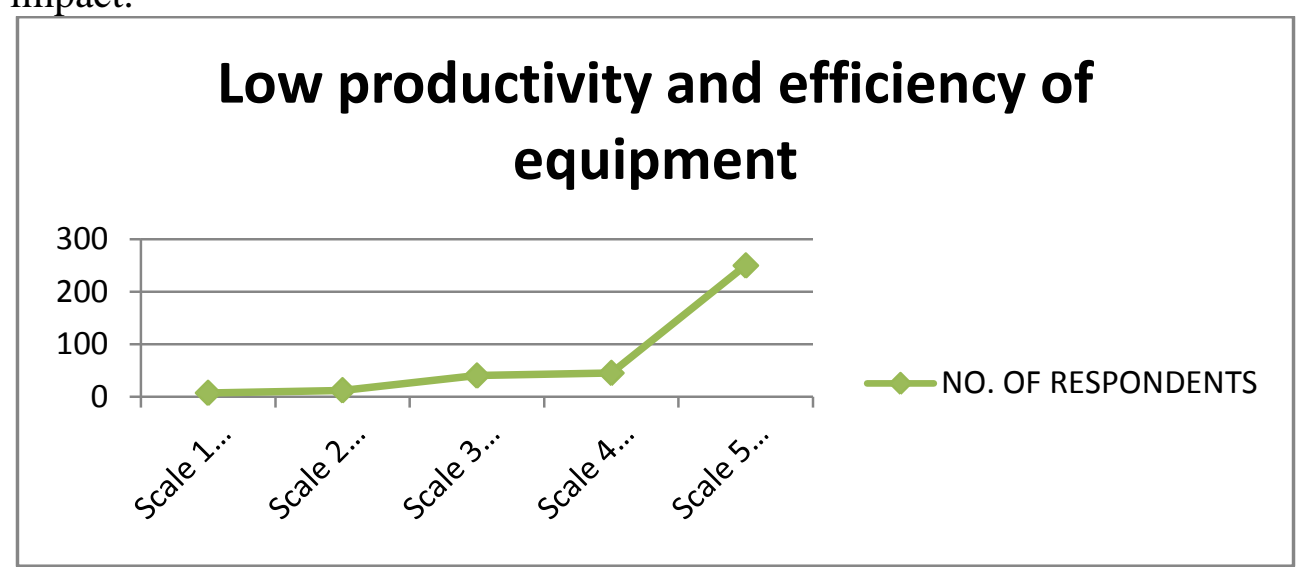

Figure 4.19: Figure showing the response on low constructability of design by the designer, Low productivity and efficiency of equipment and their effect on construction projects. 
Interpretation: Above table and graph showing the respondent response on Low constructability of design by the designer, Low productivity and efficiency of equipment would cause impact.

Six Sigma Contraptions: This situation in Six Sigma is shorted out through the proper define the function. In the define phase the improvement process is taken in to consideration by applying the tools such project charter, Deployment map, Tree diagram of project resources. In this function the following problems is mainly taken into consideration as 1 . Define the problem by developing a required 'Problem Statement'. 2. Then next to it is Define the goal by producing the 'goal statement' 3. Define the process by developing maps of project progress. 4 . Define the patron and its requirements.

Q20. Inadequate staff experience, Lack of high technology mechanical equipment, within the Project Management Team would cause impact on time delay and cost overrun of the project.

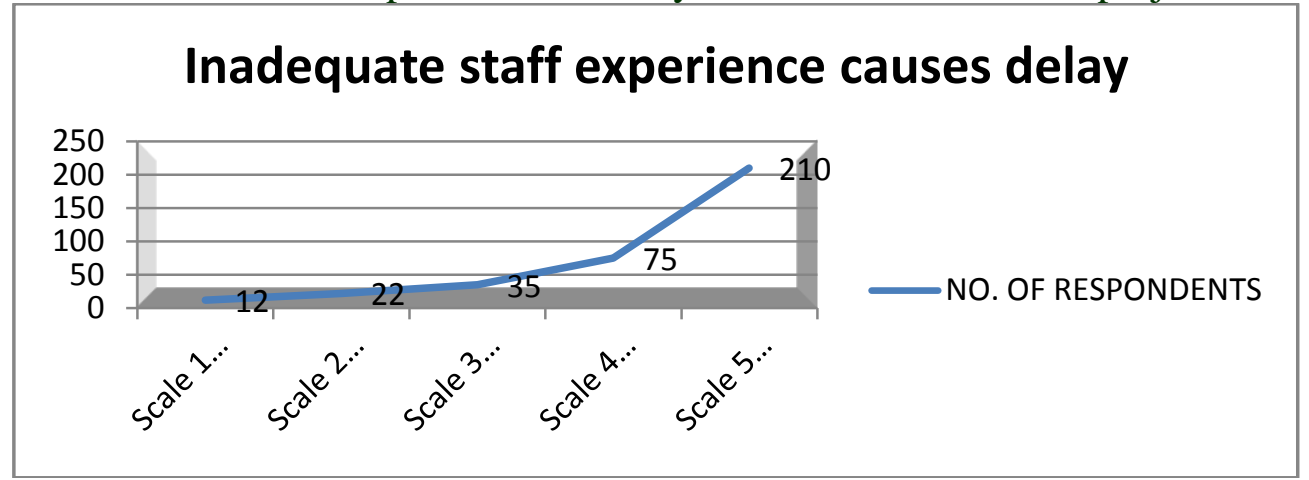

Figure 4.20: Figure showing the response on inadequate staff experience, Lack of high technology mechanical equipment, within the Project Management Team would cause impact on time delay and cost overrun of the project.

Interpretation: Above table and graph showing the respondent response on inadequate staff experience, Lack of high technology mechanical equipment, within the Project Management Team would cause impact on time delay and cost overrun of the project.

Six Sigma Contraptions: Proper instruction and training about the project to the personnel is required along with Design Failure Mode and Effect Analysis training to the contractor and sub contractor is required, for smooth and proper functioning of the project.

\section{CONCLUSION}

Dedicated Resources of project: In order to make Six Sigma services to perform, management must execute dedicated personnel to lead projects and advisers others who are working to make construction process improvements. This can be lead through an employee with such a dual task will usually focus on day-to-day performance rather than process improvement projects. In the project management the Six Sigma requires a dedication to focusing on process improvement so that day-to-day problems are solved once and for all.

Essentials of Training: For proper functioning of Six Sigma it is essential to have appropriate training is an indispensable part of a Six Sigma deployment. Quite a few aspects of the training plan must be considered. For example: what is the objective of training? Who will get this training and in what order? Will every personnel receive the same training? If not, what are the criteria for who receives each and every level or type of training? How will the training program be structured and which 
regions will receive the most attention? What will be the training duration? What methods, format, case studies, training aids will be used during this training session? Who will conduct the training consultants or internally trained personnel? What are the main selection criteria for choosing instructors?

These are some of the few questions that should be taken into account when evaluating the training plan for the project management in construction function. Project Alignment: As Six Sigma is initiated and personnel are trained, numerous ideas for construction projects improvement may be generated. To sustain as in improvement cycle PDCA (Plan, DO, Check, Act) cycle in maintained at each and every steps of the process so that the proper functioning is utilized. In the conclusion it is said that the implementation of 6 sigma in the construction section is very impressive and mark on the effectiveness of the projects and sustain of highly reliable procedures.

\section{REFERENCES}

1)_Abdalla, M.O., Hussien, T. B. (2002). Causes of construction delay: traditional contracts. International Journal of Project Management 20,67-73.

2) Apak, S., Tuncer, G., Atay, E.(2012). Hydrogen Economy and Innovative Six Sigma Applications for Energy Efficiency. International Conference on Leadership, Technology and Innovation Management, 41, 410 - 417.

3) Dinakar, A.(2014). Delay Analysis in Construction Project. International Journal of Emerging Technology and Advanced Engineering, Volume 4, Issue 5, 784-788.

4) Divya, .R, \& Ramya, S. (2015). Causes, Effects and Minimization of Delays in Construction Projects. National Conference on Research Advances in Communication, Computation, Electrical Science and Structures, 47-53.

5) Hafez, S. M., Elsaka, H. M.(2013). Identifying potential delay situations in advance to define construction contract obligations of public buildings. International Journal of Education and Research Vol. 1 No. 9. 1-8.

6) Haseeb, M., Xinhai-Lu, Bibi, A., Maloof-ud-Dyian, \& Rabbani, W.(2011). Causes and Effects of Delays in Large Construction Projects of Pakistan. Kuwait Chapter of Arabian Journal of Business and Management, Review Vol. 1, No.4,18-42.

7) Hegazy, S.(2012). Delay analysis Methodology in UAE construction Projects: Delay Claims, Literature Review. Delay Analysis Methodology in UAE Construction Projects, Vol. I, Issue II,121.

8) James, O., Lekan M. A., Oloke C. O., Olusanya, O., Tunji- Olayeni P., O. Dele., Joy .P., OmuhIgnatious (2014). Causes and effect of delay on project construction delivery time. International Journal of Education and Research, Vol. 2 No. 197-208.

9) Jonny., Christyanti. J. (2012). Improving the Quality of Asbestos Roofing at PT BBI Using Six Sigma Methodology. Social and Behavioural Sciences, 65 (2012) 306 - 312.

10) Krogstie, L., Martinsen, K.,(2013). Beyond Lean and Six Sigma; Cross-Collaborative Improvement of Tolerances and Process Variations - A Case Study, Procedia CIRP 7, 610 - 615.

11) Mehrabi, J.(2012). Application of six-sigma in educational quality management. Social and Behavioral Sciences, 47 ( 2012 ). 1358 - 1362.

12) MILI, K.(2014) Six Sigma Approach for the Straddle Carrier Routing Problem. Social and Behavioral Sciences, 111, $1195-1205$.

13) Prakash Rao, B., \& Joseph, C. C. (2014). Causes of delays in construction projects- A case study. International Journal of current research, Vol.6, Issue, 06, pp. 7219-7222. 
14) Ratnaningtyas, D. D., Surendro, K.(2013). Information Quality Improvement Model on Hospital Information System using Six Sigma, Procedia Technology 9,1166 - 1172.

15) Rohini, R., Mallikarjun, J.(2011). Six Sigma: Improving the Quality of Operation Theatre. International Conference on Asia Pacific Business Innovation \& Technology Management, 25, $273-280$.

16) Salunkhe, A. A., \& Patil, R. S.(2014). EFFECT OF CONSTRUCTION DELAYS ON PROJECT TIME OVERRUN: INDIAN SCENARIO. International Journal of Research in Engineering and Technology, Volume: 03 Issue: 01, 543-548.

17) Salunkhe, A. A., Patil. R. S.,(2013). Statistical Methods for Construction Delay Analysis. IOSR Journal of Mechanical and Civil Engineering, Volume 9, Issue 2, 58-62.

18) Seung, H. H., Myung, J. C., Keon, S. I., \& Ho D. R.(2008). Six Sigma-Based Approach to Improve Performance in Construction Operations, JOURNAL OF MANAGEMENT IN ENGINEERING, Vol. 24, No. 1, 21-31.

19) Tenera, A., Pinto, L. C.(2014). A Lean Six Sigma (LSS) project management improvement model. Social and Behavioral Sciences 119, 912 - 920.

20) Vasilyeva-Lyulina, A., Onishi, M. \& Kobayashi, K. (2015) Delay Analysis Methods for Construction Projects: Mathematical Modelling. International Journal of Transportation Vol.3, No.1, 27-36.

21) Yusr, M., Othman, A. R., \& Mokhtar, S. S. M (2012). Assessing the relationship among Six Sigma, Absorptive Capacity and Innovation Performance. International Congress on Interdisciplinary Business and Social Science, 65, 570 - 578. 